\title{
A ATUALIDADE DE MARCUSE: CONTRARREVOLUÇÃO E RESISTÊNCIA
}

\section{ROBESPIERRE DE OLIVEIRA ${ }^{1}$}

RESUMO: Este artigo busca mostrar a atualidade de Marcuse, desenvolvendo o tema da contrarrevolução apontado por ele. A dialética entre libertação e contenção é elaborada pelo autor que se preocupou com questões relativas à sociedade de consumo, considerada como uma sociedade de dominação ideológica, por meio da mídia e indústria cultural, mas que também se articula por meio da repressão interna e externa. A resistência à agressão da sociedade administrada surge no desenvolvimento de uma nova sensibilidade e da recusa dos supostos benefícios dessa mesma sociedade.

PALAVRAS-CHAVE: Marcuse, sociedade unidimensional, contrarrevolução, nova sensibilidade.

ABSTRACT: This article aims to show Marcuse's actuality, developing the theme of counterrevolution in the way he pointed out. The dialectics between liberation and contention is elaborated by the author who had concerned with the issues of consuming society, a society of ideological domination through media and culture industry. A society that also articulates internal and external repression. Resistance to the aggression of administered society comes up in the development of a new sensibility and the refusal of the supposed benefits of this very society.

KEYWORDS: Marcuse, one-dimensional society, counterrevolution, new sensibility.

\begin{abstract}
"O mundo ocidental atingiu um novo estágio de desenvolvimento: agora, a defesa do sistema capitalista requer a organização da contrarrevolução interna e externa. Em suas manifestações extremas, pratica os horrores do regime nazista. Massacres por atacado na Indochina, na Indonésia, no Congo, na Nigéria, no Paquistão, e no Sudão são desencadeados contra tudo que é chamado "comunista" ou que está em revolta contra governos subservientes aos países imperialistas. A perseguição cruel prevalece nos países da América Latina sob ditaduras militares e fascistas. A tortura se tornou um instrumento normal de 'interrogação' ao redor do mundo. A agonia das guerras religiosas revive no auge da civilização ocidental, e um fluxo constante de armas dos países ricos para os países pobres ajuda a perpetuar a opressão da libertação nacional e social." (Marcuse) ${ }^{2}$
\end{abstract}

Os desdobramentos da sociedade contemporânea, como o crescimento da direita, o ataque aos trabalhadores, às chamadas minorias, o poder do Estado ocupado por máfias 
corruptas, a imposição de retrocessos sociais e culturais, podem ser comparados a outros períodos históricos como na época da ascensão do nazi-fascismo e de regimes autoritários. Um dos diferenciais, hoje, é a ampla utilização da tecnologia, da mídia, que buscam esconder ou camuflar esses ataques como parte de um sistema "democrático". A pós-verdade tornou-se quase um símbolo desse processo. Ao contrário dos líderes nazifascistas, que proclamavam sua ideologia racista, sexista, homofóbica, hoje os políticos, que defendem tais preconceitos para toda a sociedade, se dizem democráticos. Defendem sua visão política exigindo a "escola sem partido", defendem sua visão religiosa conservadora por meio da "liberdade de religião", defendem a intervenção militar autoritária por meio da "liberdade de expressão", desculpamse de serem homofóbicos, racistas, machistas, porque estavam "brincando". Nos EUA, os sulistas defendem seu direito à bandeira Confederada como lembrança da tradição de seus antepassados, uma tradição escravagista. Muitos querem ser "democráticos" ao defender "all lives matter" contra a insígnia do "Black Lives Matters", da mesma forma que os homofóbicos dizem que se deve defender também os héteros, ou quando se diz que não se deve ser feminista, mas humanista. Tais questões de disfarce da ideologia fascista se espalham, em maior ou menor grau pelo mundo, a ponto de grupos oprimidos apoiarem ao poder aqueles que são manifestamente contra esses próprios grupos. A mídia, considerada como meio de distribuição de informação e cultura, tornou-se um elemento de força no Estado, um quarto poder, como antevisto por Joseph Goebbels, ministro da propaganda alemã, principalmente quando é autoritária e totalitária, sendo manipuladora da consciência de seus receptores.

Ao mesmo tempo, a concentração de renda no capitalismo atual tem aumentado drasticamente a ponto de $1 \%$ da população mundial deter quase metade da riqueza global. A perspectiva, no entanto, é que se concentração se intensifique. Se a burguesia clássica ainda possui alguma consciência social, em termos de investir em sua própria sociedade, a burguesia atual é cada vez mais predatória. A inovação tecnológica aumentou imensamente a capacidade da sociedade capitalista avançada para produzir mercadorias. Sociedades desiguais e repressivas também se reproduzem através da produção e negociação de dispositivos comerciais como tablets e smart phones, produção da qual também aumenta a exploração de mais-valia. Emmanuel Saez e Thomas Piketty documentaram que nos EUA de hoje cerca de metade dos ganhos que a economia produz é canalizado para os 10 por cento mais ricos. ${ }^{3} \mathrm{Na}$ maioria do mundo, as condições da classe trabalhadora são muito piores e a parte da força de trabalho da renda nacional é cada vez mais desigual. Enquanto nos EUA as 
pessoas são grandes consumidoras de produtos da Apple, estes produtos são fabricados sob condições atrozes na China. ${ }^{4}$ Muitas mercadorias vendidas na maioria dos países são feitas por trabalhadores que recebem salários extremamente baixos, quase escravos (incluindo crianças).

Muitas das questões colocadas hoje foram antecipadas na obra de Herbert Marcuse, que, em sua teoria crítica, buscou analisar criticamente a sociedade industrial avançada e formular possibilidades de mudança social. No final dos anos 1960, Marcuse já antevia o desenvolvimento do processo de contrarrevolução mundial, como se vislumbrasse a ponta do iceberg com que nos deparamos hoje. Podemos considerar a contrarrevolução como um processo geral inaugurado como resposta à Revolução Russa de 1917. Esse processo foi oculto ou aberto, por meios ideológicos ou com o uso de força. Trata-se de uma reação à possibilidade de mudança social. Em seu projeto, escrito em parceria com Franz Neumann, Teorias da Mudança Social (1941-42), há uma descrição de diversas teorias sobre a mudança social. O que há em comum a elas é o a perspectiva racionalista, crítica, que visa à felicidade como algo privado e social, que pensa a totalidade. Em contraposição à mudança social, há teorias que visam a estabilidade social, conservadoras, muitas vezes retrógradas, como reação à demanda por mudança, tal é o caso das teorias contrarrevolucionárias francesas (em referência à Revolução de 1789), ou mesmo das teorias que defendiam a soberania da Igreja no período medieval. São teorias que defendem a estabilidade da ordem com a manutenção de direitos e privilégios de uma determinada casta social, incluindo seus valores. Certamente, esta apresentação abreviada comete falhas devido a este resumo grosseiro, as teorias não são homogêneas, nem necessariamente cooperam entre si, mas é um esquema útil para compreender as disputas teóricas em jogo. Neste sentido, o marxismo é entendido por Marcuse e Neumann como uma teoria da mudança social, crítica e racionalista, que visa a transformação racional da sociedade para a felicidade de todos. Cabe, no entanto, enfatizar que a Revolução Russa foi um ensaio nessa direção, cheio de contradições e disputas internas e externas, o que não significa a realização da teoria na prática, sendo um processo aberto ainda por ser concretizado. Assim, como na Revolução Francesa, a reação à Revolução Russa deriva do medo da perda de direitos e privilégios das castas à frente do poder, incluindo a burguesia e a pequena burguesia e, diríamos, até as classes médias que se consideram parte da esfera do poder econômico. Além da questão econômica, estava em disputa questões sociais, por exemplo o direito das mulheres. $\mathrm{O}$ direito ao voto das mulheres e a participação ativa dessas na sociedade, até o comportamento autônomo e emancipado delas, assustaram os 
defensores da moral e dos bons costumes. Com a Revolução Russa, mesmo a democracia foi posta em cheque, ao se exigir maior participação popular na vida política e social. A democracia ocidental, como a europeia e a dos Estados Unidos, já havia se configurado em democracia autoritária, na qual um pequeno grupo tomava à frente dos interesses do Estado. As forças reacionárias, com suas contradições, e levadas pelo processo geral de crise dos anos 1920, acabaram por configurar Estados autoritários, incluindo a URSS.

Marcuse analisou o Estado Nacional Socialista alemão, em Estado e Indivíduo sob o Nacional Socialismo (1942), mostrando as contradições deste. A abolição do tabu sobre o sexo foi um aspecto interessante e contraditório na medida em que, segundo Freud, o controle sobre o tabu da sexualidade serviria como controle social. Mas a abolição do tabu sobre o sexo na Alemanha nazista servia a propósitos da eugenia social, e era fortemente controlado pelo Estado. Assim, era incentivada as relações sexuais intra e extraconjugais, acampamentos de jovens, orgias, reconhecimento de filhos fora do casamento, de mães solteiras, ao mesmo tempo, os homossexuais eram excluídos, bem como todas as relações e procriações só eram admitidas entre arianos. As mulheres também tinham um papel ativo, embora fossem designadas aos três Ks (Küche, Kirsche, Kindern - cozinha, igreja e crianças). As contradições do Estado nazista mostram como tais contradições fazem parte, embora não sejam determinantes do próprio Estado, pois ao mesmo tempo em que aparentava liberalidade em relação ao sexo, o Estado era extremamente conservador, valorizando a tradição de um passado mítico. ${ }^{5}$

O esforço do marxismo ocidental, incluindo os teóricos críticos, foi buscar compreender criticamente o fascismo e combatê-lo, daí a grande preocupação com a questão da consciência, da racionalidade, da ideologia e dos meios culturais. Marcuse escreveu Razão e revolução (1941) como resposta àqueles que vinculavam a filosofia negativa de Hegel às origens do nacional socialismo. Para ele, a filosofia positiva, que segue uma racionalidade instrumental, estaria na base de teóricos do nacional socialismo. Seus ensaios dos anos 1930, a partir de seu ingresso no Instituto de Pesquisas Sociais de Frankfurt, tratam da ideologia repressiva do nacional socialismo, como o ensaio $\mathrm{O}$ combate ao liberalismo na visão totalitária do Estado (1934), no qual desenvolve a tese segundo a qual o nacionalismo socialismo não é contrário ao liberalismo, mas sim seu desenvolvimento ulterior.

Durante seu trabalho para o governo norte-americano nos anos 1940, Marcuse chegou a desenvolver um projeto de desnazificação da Alemanha pós-guerra, que previa o 
fortalecimento da sociedade civil, com sindicatos e partidos livres. O receio do governo dos EUA frente a URSS impediu que esse projeto fosse realizado, ao invés, os EUA preferiram recolocar ex-nazistas de baixo escalão em postos administrativos. Assim, a perspectiva de um mundo mais livre e pacífico após a Segunda Guerra Mundial se perdeu. Em suas 33 Teses” (1947) sobre a situação contemporânea, ${ }^{6}$ Marcuse expõe o que virá a ser a Guerra Fria. Para ele, o mundo do pós-guerra se dividiria em dois campos: o soviético e outro neofascista, sendo as formas democrático-liberais absorvidas por um deles.

Segundo Stanley Aronowitz, aparentemente tal "predição" não teria se cumprido na medida em que teria havido a expansão da democracia para diversos países, incluindo excomunistas. Entretanto, Aronowitz não observa que os países que citou, como Argentina, México, e Brasil, tornaram-se democráticos após longo período ditatorial. Muitos países sofreram golpes de Estado, instalando ditaduras militares, numa pretensa luta contra o comunismo, quando Marcuse ainda estava vivo. O processo democrático nesses países, bem como nos ex-comunistas, ocorreu anos após sua morte. Mas Aronowitz observa que a concepção de Marcuse de fascismo difere da usual. ${ }^{7}$ Deste modo, as democracias atualmente existentes não correspondem para Marcuse ao modelo da democracia liberal, ao invés disso, ele as considera como democracias autoritárias ou mesmo totalitárias. Tal modelo corresponderia ao que Max Weber imaginava suceder nas democracias capitalistas, isto é, democracias plebiscitárias, nas quais a escolha do povo segue decisões previamente estabelecidas. Além disso, o modelo democrático vigente, a partir da maior potência mundial, tem oprimido minorias, em nome da liberdade, principalmente pela desigualdade econômica prevalecente.

Embora o campo soviético, mesmo corrompido, ainda representasse uma esperança para a esquerda em geral, Marcuse acreditava que esse campo em competição com o capitalismo acabaria por ser derrotado, por não estar em igualdade de condições. Seu ceticismo em relação ao campo soviético baseava-se não só na distorção da teoria marxista, mas também na burocratização do Estado, cujo caráter autoritário impedia a liberdade dos próprios trabalhadores. Mesmo assim, nas teses, havia ainda uma esperança no movimento operário no interior dos países do "socialismo real", bem como na possibilidade revolucionária. Em suas propostas, ele parece manter-se ao lado de Rosa Luxemburg com relação à consciência e organização da classe. 
De fato, os partidos comunistas apareciam como uma forte referência aos trabalhadores, enquanto seus opositores, como os trotskistas, compunham um grupo muito pequeno e fraco. Os partidos comunistas, de certo modo, estavam ainda atrelados ao partido soviético, de tal modo que muitos ficaram chocados com o pronunciamento de Krushev, na década de 1950, revelando os crimes de Stálin. O propósito disso não era nem o socialismo nem a democratização, mas sim a reestruturação da burocracia no poder. A União Soviética e os Estados Unidos levaram o mundo a um equilíbrio delicado, em função da competição econômica e militar, de tal modo que o caráter unidimensional ${ }^{8}$ servia a ambos Estados, apesar do controle e manipulação se darem diferentemente. Esse caráter unidimensional refere-se à paralisia da oposição que ou não tem força ou não tem qualidade para se pôr como tal.

A esquerda revolucionária acreditou nos movimentos de libertação colonial e de luta contra o imperialismo norte-americano e soviético. As guerrilhas e a luta armada pareciam responder ao anseio de que a revolução estava próxima. Muitos intelectuais também ficaram impressionados, à esquerda ou à direita, com este movimento, do qual a Revolução Cubana foi um marco. Apesar do anseio utópico de Marcuse pela transformação da realidade social, sua descrição crítica da realidade unidimensional da sociedade industrial avançada foi considerada pessimista em relação à perspectiva revolucionária. Em certo sentido, estava medindo as forças contrarrevolucionárias, percebendo que seu poder de rearranjo e dominação era muito mais ágil do que a fraca oposição. Assim, Contrarrevolução e revolta (1974) continua o debate iniciado com O homem unidimensional (1964). Passados quase cinquenta anos, Maio de 1968 continua sendo apreciado como um símbolo de rebeldia com o qual a imaginação pretendeu o poder. Mas esses que louvam Maio de 1968 parecem se esquecer do violento processo contrarrevolucionário que se lhe seguiu, tanto no âmbito ideológico, político, econômico, sexual e cultural.

Em O homem unidimensional, Marcuse destaca três características fundamentais: o pensamento, a educação e o comportamento unidimensionais. O livro trata fundamentalmente da sociedade industrial avançada, na qual a racionalidade tecnológica e o consumo de mercadorias desenvolvem um processo de adaptação à sociedade opressora dos indivíduos que nela vivem. A sensação de "liberdade" está relacionada à proteção (segurança) que os indivíduos acreditam possuir, mesmo sendo vigiados, confinados em abrigos antibombas, ou, mais recentemente, a submeterem sua privacidade ao Estado. O consumo de mercadorias também provê essa sensação de "liberdade" e "felicidade", e identifica seus consumidores em 
grupos, na mesma medida em que os molda. Georg Lukács, em História e consciência de classe (1923), já havia mostrado como a mercadoria havia se transformado em forma fenomênica da estrutura da sociedade capitalista. O consumo de mercadorias tornado universal moldou o comportamento dos homens, desde seu alimento, roupas, a entretenimento. Marcuse estabelece a distinção entre verdadeiras e falsas necessidades. Os homens precisam satisfazer suas necessidades, e o fazem, na sociedade capitalista, mediante o mercado, a maioria pela venda da força de trabalho. As verdadeiras necessidades seriam aquelas necessidades básicas de sobrevivência, alimentação, moradia, saúde. As falsas necessidades são aquelas supérfluas, adicionadas pela crescente produção de mercadorias, e que atam os indivíduos ao sistema de opressão. Geralmente, essas estão vinculadas à tecnologia, cuja obsolescência planejada desenvolve a necessidade de um ciclo de troca interminável: substituir o carro, o televisor, o celular, o computador; além da crescente introdução de novos gadgets. A felicidade e liberdade fornecidas, sendo externas ao indivíduo, também são falsas, embora sejam verdadeiras para o indivíduo.

Assim, Marcuse, a partir de Marx, afirma que a relação entre homem-objeto foi substituída pela relação homem-mercadoria, o mundo objeto passou a ser mundo-mercadoria. ${ }^{9}$ Até a própria natureza foi reduzida à forma mercantil. A natureza tornou-se estranha enquanto a tecnologia parece cada vez mais natural. A racionalidade tecnológica, que visa produtividade, eficiência e lucro, não só produz uma adaptação dos indivíduos à sociedade de dominação, como também desumaniza, reificando os indivíduos, na medida em que estão inseridos num ciclo constante de trabalho alienado. Ao invés da tecnologia libertar os indivíduos para uma vida pacificada, livre e feliz, os insere cada vez mais nas contradições da exploração cotidiana.

Associada à racionalidade tecnológica, está a indústria cultural, cuja elaboração formulada por Horkheimer e Adorno na Dialética do esclarecimento (1947). A indústria cultural complementa a racionalidade tecnológica mediante a propaganda de seus produtos e sua naturalização. Tecnologia não se refere exclusivamente a aparelhos, mas também a métodos e procedimentos. A indústria cultural opera com valores que são imbuídos nos espectadores, os quais geralmente são mais receptivos do que ativos ou críticos. A indústria cultural faz parte do processo formativo (ou de deformação) dos indivíduos, que, da mesma forma que a tecnologia, oferece produtos que requerem pouco esforço reflexivo. Douglas Kellner, em A cultura da mídia (1995), busca reformular o conceito de indústria cultural expandindo-o para a cultura da mídia. Segundo Kellner: 
Há uma cultura veiculada pela mídia cujas imagens, sons e espetáculos ajudam a urdir o tecido da vida quotidiana, dominando o tempo de lazer, modelando opiniões políticas e comportamentos sociais, e fornecendo o material com que as pessoas forjam sua identidade. $\mathrm{O}$ rádio, a televisão o cinema e os outros produtos da indústria cultural fornecem os modelos daquilo que significa ser homem ou mulher, bem-sucedido ou fracassado, poderoso ou impotente. A cultura da mídia também fornece o material com que muitas pessoas constroem o seu senso de classe, de etnia e raça, de nacionalidade, de sexualidade, de 'nós' e 'eles'. Ajuda a modelar a visão prevalecente de mundo e os valores mais profundos: define o que é considerado bom ou mau, positivo ou negativo, moral ou imoral. As narrativas e as imagens veiculadas pela mídia fornecem os símbolos, os mitos e os recursos que ajudam a constituir uma cultura comum para a maioria dos indivíduos em muitas regiões do mundo de hoje. A cultura veiculada pela mídia fornece o material que cria as identidades pelas quais os indivíduos se inserem nas sociedades tecnocapitalistas contemporâneas, produzindo uma nova forma de cultura global.

Essa cultura é constituída por sistemas de rádio e reprodução de som (discos, fitas, CDs e seus instrumentos de disseminação, como aparelhos de rádio, gravadores, etc.); de filmes e seus modos de distribuição (cinemas, videocassetes, apresentação pela TV); pela imprensa, que vai de jornais a revistas; e pelo sistema de televisão, situado no cerne desse tipo de cultura. Trata-se de uma cultura da imagem, que explora a visão e a audição. Os vários meios de comunicação — rádio, cinema, televisão, música e imprensa, como revistas, jornais e histórias em quadrinhos privilegiam ora os meios visuais, ora os auditivos, ou então misturam os dois sentidos, jogando com uma vasta gama de emoções, sentimentos e idéias. A cultura da mídia é industrial; organiza-se com base no modelo de produção de massa e é produzida para a massa de acordo com tipos (gêneros), segundo fórmulas, códigos e normas convencionais. É, portanto, uma forma de cultura comercial, e seus produtos são mercadorias que tentam atrair o lucro privado produzido por empresas gigantescas que estão interessadas na acumulação de capital. A cultura da mídia almeja brochuras, educação grande audiência; por isso, deve ser eco de assuntos e preocupações atuais, sendo extremamente tópica e apresentando dados hieróglifos da vida social contemporânea. ${ }^{10}$

A longa citação foi necessária para clarificar o significado da mídia como um poder predominante na sociedade contemporânea. Embora não tivesse elaborado muito sobre isso, Marcuse tinha o conhecimento da crescente ascensão da influência dos chamados meios de comunicação, como a indústria cultural, termo que ele pouco utilizou. ${ }^{11}$ De fato, para ele, a cultura se tornou dessublimada e repressiva na sociedade contemporânea. Segundo Marcuse,

A sociedade está eliminando as prerrogativas e os privilégios da sociedade feudalaristocrática junto com seu conteúdo. O fato de que as verdades transcendentes das belas artes, as estéticas da vida e do pensamento fossem acessíveis a apenas uns poucos ricos e educados era a falha de uma sociedade repressiva. Mas essa falha não é corrigida por brochuras, educação geral, discos long-playing, e a abolição do traje a rigor nas salas de concerto. Os privilégios expressaram a injustiça da liberdade, a contradição entre ideologia e realidade, a separação da produtividade material e intelectual; mas eles também ofereceram um reino protegido no qual as verdades proibidas puderam sobreviver em uma integridade abstrata - distanciadas da sociedade que as suprimia. 
(...) A alienação artística tornou-se tão funcional quanto a arquitetura dos novos teatros e salas de concerto nos quais ela é executada. E aqui também, o racional e o mal são inseparáveis. Inquestionavelmente, a nova arquitetura é melhor, isto é, mais bonita e mais prática do que as monstruosidades da era vitoriana. Mas ela é também mais "integrada" - o centro cultural está se tornando uma parte incorporada do shopping center, do centro municipal ou governamental. A dominação tem sua própria estética e a dominação democrática tem sua estética democrática. É bom que quase todos possam ter as belas-artes a seu alcance, girando ou pressionando um botão em seu aparato, ou entrando em uma loja qualquer. Nessa difusão, entretanto, elas se tornam engrenagens de uma máquina cultural que refaz seu conteúdo. ${ }^{12}$

O acesso democrático está associado ao processo de integração à sociedade. A própria educação unidimensional é integradora. Trata-se de uma educação que visa desenvolver e habilitar o indivíduo para a sociedade, para o trabalho e para o consumo. Uma educação crítica, ao contrário, deve fornecer um processo formativo, reflexivo que possibilite a autonomia do indivíduo, incluindo a reflexão e crítica social para a transformação da realidade social em que vive. Vários autores, como Douglas Kellner e Charles Reitz, se dedicam a elaborar a perspectiva educacional de Marcuse. Alguns chegam a ver similaridades com Paulo Freire. No livro Marcuse's Challenge to Education (2009), ${ }^{13}$ foram publicadas duas palestras de Marcuse, além de ensaios sobre o autor. A primeira, de 1968, era mais voltada para a libertação e enfatizava o papel crítico e reflexivo da educação, colocando questionamentos sobre as relações sociais e a democracia existente. A segunda, de 1975, estava mais preocupada com o processo de contrarrevolução. Eu cito:

Agora, sugiro que tais mudanças estão verdadeiramente acontecendo, não só entre a juventude, intelectuais, etc., mas entre a população dependente como um todo. $\mathrm{O}$ povo está se tornando consciente do fato que ele não deve gastar sua vida em desempenhos mecânicos, mortalmente desumanizantes em fábricas, escritórios, etc., que não deve ficar num ambiente poluído, que a sociedade é rica o suficiente para acabar com as pressões e repressões impostas durante os períodos anteriores de escassez. Em resumo, a fé na necessidade, nos valores básicos do capitalismo, está desmoronando.

Este enfraquecimento da coesão e da integração social, a emergência de uma nova consciência, e das novas necessidades incompatíveis com o sistema, emergiu como uma força política ameaçadora sobre a escala global nos 1960. Os dominantes reconheceram o perigo melhor do que os rebeldes, e responderam com o aperfeiçoamento e cientificação da repressão (o período da contrarrevolução). Nesta reorganização reacionária do capitalismo monopolista, a supressão violenta é apenas o último recurso. De outro modo, confia-se na pressão econômica e nos controles eletrônicos. Grande ênfase é dada à educação. $\mathrm{O}$ trabalho intelectual representa um crescente papel no processo social de reprodução. A mente, que ganha crescente valor de uso, deve ser tomada em mãos. Mesmo em sua dimensão inconsciente, deve ser desviada de suas possibilidades de libertação. ${ }^{14}$ 
Marcuse alerta para o papel de resistência da educação e do intelectual comprometido com a mudança social na época da contrarrevolução. $\mathrm{O}$ ataque a uma educação reflexiva e crítica é um dos primeiros passos do ataque da contrarrevolução. A demanda de grupos por reconhecimento, como negros, LGBTQs, mulheres, entre outros vem das necessidades desses grupos para se inserirem democraticamente na sociedade. Entretanto, o não reconhecimento de direitos desses grupos reforça a estrutura de poder dominante das forças contrárias à mudança social.

Para Marcuse, a educação deveria estar voltada para princípios éticos universais, baseando-se na solidariedade, portanto, voltada para a justiça social, o reconhecimento da diversidade. Assim, ele defende o estudo da história dos oprimidos e das lutas sociais. Tal como na filosofia de Platão e Aristóteles, trata-se de mirar o bem comum, utilizando-se do instrumental crítico da filosofia para fazer o discernimento necessário. Em O homem unidimensional, Marcuse discute a filosofia da linguagem à luz do uso ideológico da linguagem, ao mesmo tempo em que critica a filosofia tradicional da linguagem e a filosofia analítica. Para ele, a relação entre conteúdo e forma é por vezes distorcida no contexto da sociedade unidimensional. Ele cita o caso do "Pai da bomba H", em que a figura paterna, portadora de afetos, é associada a uma arma de destruição em massa. A linguagem orwelliana, na qual há inversão dos significados ("guerra é paz", "liberdade é escravidão", "ignorância é força"), predomina nos discursos políticos e midiáticos. Democracia é reivindicada por autoritários; liberdade é invocada para impor uma visão única a todos. Os exemplos multiplicam-se. O discurso unidimensional é excludente, sem preocupação com a história ou com a verdade. Hoje, essa análise mostra-se com mais vigor com a multiplicação de notícias falsas e a pós-verdade.

A ideologia se tornou dominante com o processo de integração e contenção da sociedade unidimensional. Integração por meio do consumo, da produção tecnológica, e pela manipulação dos meios de comunicação e distribuição de bens culturais. Mas o controle do poder não se sustenta apenas na base do "pão e circo", quando a indústria cultural não consegue ter influência, é necessário o uso da força. O poderio militar interno e externo tornase fundamental (“guerra é paz"). A manipulação das fontes de informação é essencial ao controle ("ignorância é força). Desde Goebbels, sabe-se da potência do uso da propaganda. Entretanto, o uso da força é um meio mais eficiente para impor a opressão dos setores dominantes da sociedade, que não querem fazer mais concessões com receio de perderem seu status. 
O período de contrarrevolução aberto que surgiu no final dos anos 1960 e tomou fôlego com a política do neoliberalismo, cujo principal nome foi o de Margaret Thatcher, teve um forte avanço militar onde a indústria cultural não chegava. Ao mesmo tempo, buscou eliminar as bases do chamado Estado de Bem-Estar Social (Welfare State). Contrarrevolução não significa aqui um movimento de reação a uma revolução existente, mas sim o ataque agressivo aos direitos e o aumento da exploração e opressão. Em parte, esse processo resulta como medo da inclusão maior de setores apartados da sociedade; em parte, como consequência das crises econômicas do capitalismo. Segundo Marx, as crises econômicas do sistema capitalista são estruturais, consequência do crescimento mesmo da economia, que é seguido pela recessão. São as chamadas ondas de crise, às vezes mais longas, às vezes menos; com períodos de tranquilidade mais largos ou não. A ascensão econômica estourou no fim dos anos 1960, com a crise do petróleo. Houve breve recuperação nos anos 1990 e retornou a crise no século XXI.

Em suas palestras em Paris em 1974, Marcuse revela sua visão do problema que será a chamada "nova ordem mundial", propalada nos anos 1980.

O capitalismo dos EUA ainda retém este poder estabilizador numa forma reorganizada, reorganizada em escala nacional tanto quanto global. Alguns indicadores desta reorganização: Em escala nacional, nos recentes anos testemunhamos uma considerável e crescente restrição aos direitos e liberdades civis pela justiça (courts), por decreto administrativo, pela legislação. Observamos uma continuada e crescente manipulação do ainda existente processo democrático, como se não houvesse bastante manipulação antes. Se é impossível ser um candidato nas eleições sem dispor de uma fortuna de cerca de um milhão de dólares, isto é em qualquer caso uma estranha forma de democracia. ${ }^{15}$

E mais adiante:

A reorganização em escala nacional é acompanhada por uma reorganização em escala global, principalmente através de novas formas de imperialismo e de colonialismo, o assim chamado colonialismo indireto, que em muitos casos parece ser mesmo mais rentável do que as formas anteriores de colonialismo, que, ao menos na América Latina, há muito tem sido substituído ou, melhor, assumido controle por classes dominantes nativas e exércitos nativos que fazem o trabalho para os países capitalistas metropolitanos. ${ }^{16}$

Tal reorganização do capital surge como necessária para repor o lucro perdido nos processos de crise. Os capitalistas não têm escrúpulos no modo como procedem a tal reorganização, mesmo que tenham que detonar guerras, ataques internos aos trabalhadores, submissão ao imperialismo, realocação de força de trabalho em outros territórios, nos quais a legislação permite maior exploração, mão de obra mais barata, etc. Esta terceirização mundial do trabalho favoreceu crescimento dos países asiáticos, que chegaram a ameaçar a economia 
norte-americana, que passou a ser uma sociedade pós-industrial na medida em que a maioria dos seus produtos eram fabricados fora de lá. ${ }^{17}$

A queda do muro de Berlim, 1989, e o fim da União Soviética, 1991, teriam sido antecipados por Marcuse quando ele critica os países "comunistas" por competirem com o capitalismo nos termos deste. Na medida em que a verdade da teoria marxista não foi realizada pela União Soviética e demais países, o fim da configuração desses países não significou o fracasso da teoria marxista, mas tão somente de sua prática política. Marcuse havia criticado o Marxismo Soviético em seu livro de 1958, no qual assume como certa a doutrina do Estado soviético para mostrar suas contradições internas e com a própria teoria marxista. Assim, o propalado "fracasso da teoria marxista" seria apenas propaganda ideológica da mídia capitalista, que também proclamou “o fim das ideologias” em 1989. Na verdade, isso não foi novidade, em O homem unidimensional (1964), Marcuse criticara Daniel Bell por proclamar "o fim das ideologias". Nem houve o "fim da história", nem desapareceram as ideologias, houve uma nova reacomodação: a chamada Nova Ordem Mundial.

De fato, a crise iniciada com a queda dos países “comunistas", levou a guerras localizadas, e a uma posterior crise econômica mundial. A guerra do Golfo, 1991, criou os inimigos necessários, segundo Chomsky, para a manutenção do sistema militar norteamericano. Tratou-se da substituição dos "comunistas" como inimigos externos pelos "terroristas árabes", cujo desenvolvimento levou ao 11 de setembro de 2001 e à guerra ao terror de G. W. Bush. Logo, percebeu-se a fragilidade da nova ordem mundial. Em 2010 e 2011, o Occupy Movement e a Primavera Árabe pareciam a promessa de uma nova época de libertação e instituições democráticas reais, mas o que sucedeu foi um novo processo de contrarrevolução. A desorganização das sociedades arábicas, promovidas pelo desmonte do Estado iraquiano, fez surgir o Estado Islâmico (ISIS), que expandiu guerra e terrorismo e várias partes do mundo, por meio de apoiadores, atentados, e grupos semelhantes. A extrema direita cresceu no mundo, como na Ucrânia, Hungria, onde assumiram o poder e outros países em que aumentaram sua força. Novas formas de golpe de Estado, golpe branco, frio ou legislativo, surgiram na América Latina, lembrando o período dos anos 1960, em que tais países com o golpe se tornaram submissos ao poderio norte-americano. Os próprios EUA foram tomados por um presidente de extrema direita, sem experiência política de Estado, Donald Trump, com discurso homofóbico, racista, sexista, xenofóbico e dominador. 
Acompanhando essa nova fase, as questões sociais, como desempregados, refugiados, negros, mulheres e LGBTQs, estão sendo negadas, reprimidas, colocadas em terceiro plano, às vezes violentamente. Ao mesmo tempo, os governos estão sendo tomados por bandidos (Rackets), cuja teoria formulada por Horkheimer é endossada por Marcuse, que visam sua própria riqueza, defendendo o capitalismo financeiro do que o produtivo. A produção também enfrenta o dilema ambiental. Marcuse antecipou várias discussões sobre o problema da natureza, como a utilização do conceito de "obsolescência planejada", em que os produtos de tecnologia têm prazo de validade cada vez menor, mesmo se ainda estiverem funcionando. Isto cria uma desvalorização de tais produtos em pouco tempo, além do lixo eletrônico que contamina o ambiente. No Brasil, a produção de soja desmata áreas enormes de floresta, consideradas reservas de ecossistemas, oxigênio e água.

Apesar desse desenvolvimento, Marcuse continuou sua perspectiva utópica de mudança social, enfatizando a necessidade de uma nova sensibilidade e da grande recusa. Recusar os benefícios do sistema, em protesto contra ele, mas uma recusa que se deve ser coletiva e não individual. Tanto a grande recusa quanto a nova sensibilidade surgem da necessidade dos indivíduos, inclusive biológica, de quererem viver, viver melhor. A nova sensibilidade se expressa, principalmente, nos momentos de solidariedade, em apoio aos refugiados, negros, mulheres, LGBTQs, aos excluídos. Ela surge como mudanças em relação e contra os valores arcaicos vigentes na sociedade. Os indivíduos buscam novas relações éticas e de justiça social, incluindo novas relações com a natureza. A sociedade estabelecida é uma sociedade estressante que produz indivíduos psiquicamente doentes. Cada vez mais, os líderes já não se impõem como figuras de confiança, como a figura paterna. Suas contradições aparecem rapidamente. A hipocrisia dos que defendem uma moralidade que não conseguem cumprir, dos corruptos que falam contra a corrupção. Os indivíduos percebem essas contradições, como as injustiças a que estão acometidos. Por vezes, essa percepção é confusa e manipulada pela mídia e indústria cultural. Nesse sentido, Marcuse discute o papel dos intelectuais, mesmo considerando as próprias contradições deles. Assim, caberia aos intelectuais e educadores comprometidos com a justiça social, eticamente e universalmente estabelecida, assumirem seu papel, não para dirigirem, mas para fazer com que os revoltados compreendam o problema que enfrentam.

Hoje esta situação nos traz face a face com a questão da responsabilidade do intelectual. A escolha é ditada ao intelectual pelas duas faces da simbiose da ciência e da sociedade, imaginação e dominação que encontramos hoje. A escolha pode ser formulada na seguinte questão. A razão, imaginação e sensibilidade do homem estarão a serviço de uma mais eficiente e próspera servidão ou melhor 
servirão para cortar este vínculo, libertando as faculdades do homem e sua imaginação e sensibilidade desta escravidão rentável? Acredito que os estudantes militantes fizeram esta escolha e pagaram claramente por ela. Hoje, as reais possibilidades da liberdade humana são tão reais e os crimes da sociedade que impede sua realização são tão gritantes que o filósofo, o educador não pode mais evitar tomar partido, e isto significa aliança, solidariedade com aqueles que não são mais capazes de e não mais desejam seu futuro, sua existência determinadas e definidas pelas demandas do status quo. Determinadas e definidas pelos poderes, os mesmos poderes que tornam o mundo a confusão, a ameaça, e a mentira que é hoje. (...) se o filósofo, o educador ainda exercerem seriamente seu trabalho de esclarecimento, ele se encontrará se o quiser ou não com aqueles que querem dar significado e realidade às palavras e ideias que ensinou durante sua vida como educador, e não apenas significado acadêmico, mas um significado que pelo qual se deve lutar, um significado pelo qual se deve viver. ${ }^{18}$

A atualidade de Marcuse encontra-se em sua análise a sociedade unidimensional, na qual ele aponta para os problemas que enfrentamos hoje. Apesar de sua análise realista soar como pessimista, ele persegue a possibilidade de libertação e acredita que os homens e mulheres desenvolvem necessidades reais, para além das falsas imposições do sistema, mudam seu comportamento e suas relações, desejam uma vida melhor em protesto contra a existência dominada da sociedade administrada. As contradições da sociedade capitalista avançada produzem novas forças e oposição, que podem não estar totalmente organizadas para virar o jogo, mas são o primeiro passo para isso. Enquanto os poderosos atacam com violência, os proscritos buscam encontrar forças e resistir contra a ordem opressora. Citando Marcuse,

Entretanto, debaixo da base popular conservadora está o substrato dos proscritos e estrangeiros, os explorados e perseguidos de outras raças e outras cores, o empregado e o não empregável. Eles existem fora do processo democrático; sua vida é a mais imediata e a mais real necessidade pelo fim de condições e instituições intoleráveis. Assim sua oposição é revolucionária mesmo se sua consciência não é. Sua oposição atinge o sistema de fora e é, portanto, não é desviada pelo sistema; é uma força elementar que viola as regras do jogo e, ao fazer assim, revela-o como um jogo fraudado. Quando ficam juntos e vão para as ruas, sem armas, sem proteção, de modo a pedir pelos mais primitivos direitos civis, eles sabem que enfrentaram cães, pedras, e bombas, cadeia, campos de concentração, e mesmo morte. Sua força está atrás de cada demonstração policial pelas vítimas da lei e ordem. O fato segundo o qual eles começam se recusando a jogar o jogo pode ser o fato que marca o início do fim de um período. Nada indica que será um bom fim. As capacidades econômicas e técnicas das sociedades estabelecidas são suficientemente vastas para conceder ajustes e concessões para o pobre diabo, e suas forças armadas suficientemente treinadas e equipadas para cuidar de situações de emergência. Entretanto, o espectro está lá de novo, dentro e fora das fronteiras das sociedades avançadas. O paralelo histórico simples com os bárbaros ameaçando o império da civilização prejudica a questão; o segundo período de barbarismo pode bem ser o império continuado da civilização mesma. Mas a oportunidade é aquela, neste período, que os extremos históricos podem se encontrar novamente: a mais avançada consciência de humanidade e a sua força mais exploradora. É nada senão uma oportunidade. A teoria crítica da sociedade 
não possui conceito que possa fazer a ponte sobre o abismo entre o presente e seu futuro; defendendo nenhuma promessa e mostrando nenhum sucesso, ela permanece negativa. Assim ela quer permanecer leal àqueles que, sem esperança, deram e dão sua vida à Grande Recusa. ${ }^{19}$

\section{NOTAS}

\footnotetext{
${ }^{1}$ Professor associado da Universidade Estadual do Maringá (UEM). Doutor em filosofia pela Universidade de São Paulo (USP), com pós-doutorado pela City University of New York. E-mail: roliveira@uem.br.

2 MARCuSE, Herbert. Counterrevolution and Revolt, Boston, Beacon Press, 1972, p. 1.
}

${ }^{3}$ LOWREY, Annie. "Incomes Flat in Recovery, but Not for the 1\%" (2013). Para uma discussão detalhada ver REITZ e SPARTAN, "The Political Economy of Predation and Counterrevolution”, pp. 19-41. In: REITZ (2015).

4 Veja-se o caso dos suicídios na Foxconn na China em 2010 devido às condições de trabalho.

${ }^{5} \mathrm{O}$ próprio Adolf Hitler pode ser pensado em termos dessas contradições. Ele amava cachorros, era vegetariano por defender os animais, antitabagista, e incorruptível, o que não fazia dele um ser ético.

6 Marcuse, Herbert. “33 Teses”, pp. 291-303. In: Marcuse (1999).

7 "But consider how Marcuse's conception differs from the accepted views of fascism. Of course, U.S. society is not marked by a program of systematic terror against racialized minorities, although, as we have seen, the number of incidents of police violations of the rights of black men has escalated in proportion as poverty and unemployment deepens in the cities. But in other respects-such as the intensification of individualism, the decline of the labor movement and other social groups, and the emergence of a cultural environment of puritanical antisexuality-U.S. society has all the earmarks of a growing authoritarianism." Aronowitz, Stanley. “The Unknown Marcuse”, In: Social Text 58, Vol. 17, No.1, Spring 1999, pp. 133-154, p. 152.

8 "A ameaça de uma catástrofe atômica, que poderia exterminar a raça humana, também não serve para proteger as próprias forças que perpetuam esse perigo? Os esforços para impedir tal catástrofe ofuscam a busca por suas causas potenciais na sociedade industrial contemporânea. Essas causas permanecem não identificadas, nãoexpostas e não-atacadas pelo público, porque elas recuam diante da ameaça externa óbvia demais: do Ocidente para o Oriente, do Oriente para o Ocidente. Igualmente óbvia é a necessidade de se estar preparado, de se viver à beira do abismo, de encarar o desafio. Nós nos submetemos à produção pacífica de meios de destruição, ao aperfeiçoamento do desperdício, a ser educados para uma defesa que deforma os defensores e aquilo que defendem." (Marcuse, Herbert, 2015, p. 31).

9 "This is what Marx called the human "appropriation" of the object world: the establishment of human relationships with nature, the humanization of things. It means that the world is no longer experienced as a commodity market, nor men as buyers or sellers of labor power, nor things as the mere stuff of possession and use. What appears in this radically new experience is a use value no longer contaminated by exploitation: the experience that things, without losing their use value, exist in their own right, their own form - that they are sensitive. Exploitation is not really abolished, its heritage not really thrown off until man has established this new relationship to nature: the humanization of nature would also enable man to have the good conscience of his own nature, of himself as part of nature. This is the "second nature": it is not the world of the bon sauvage, but that of high civilization - the promise of freedom.” (Marcuse, Herbert. "Cultural Revolution” In: Marcuse, 2001, pp. 121-162, p. 132).

${ }_{10}$ Douglas Kellner, A cultura da mídia. Trad. Ivone Castilho Benedetti. Bauru, Editora da Universidade do Sagrado Coração, 2001. p. 9.

11 Por exemplo nessa passagem de Eros e civilização (1955): “A necessidade de relaxamento nos entretenimentos fornecidos pela indústria da cultura [indústria cultural] é em si mesma repressiva, e a sua repressão significa um passo para a liberdade. Sempre que a repressão se tornou tão efetiva que, para o reprimido, assume a forma (ilusória) de liberdade, a abolição de tal liberdade prontamente se manifesta como um ato totalitário." (Marcuse, Herbert. Eros e civilização, São Paulo, Círculo do Livro, s/d, p. 190).

12 Marcuse, O homem unidimensional, pp. 91-92.

13 Kellner et al, Marcuse's Challenge to Education. Laham, Boulder, New York, Toronto, Plymouth - UK,

Rowman and Littlefield publishers, 2009.

14 Op.cit. p. 40. 
15 Jansen, Peter-Erwin and Reitz, Charles. (eds) Herbert Marcuse's 1974, Paris Lectures at Vicennes University from Marcuse Archives. Global Capitalism and Radical Opposition. Introduction by Sarah Surak and afterwords by Douglas Kellner. Salisbury University, Maryland, USA, 2015. "U.S. capitalism still retains a considerable degree of stabilizing power. Capitalism retains this stabilizing power in a reorganized form, reorganized on the national as well as global scale. A few indications of this reorganization: On the national scale, in the recent years we have witnessed a considerable and still growing restriction on civil rights and liberties by the courts, by administrative decree, by legislation. We have observed a continued and a growing manipulation of the stillexisting democratic process, as if it would not have been manipulated enough already before. If it is impossible to become a candidate in the elections without disposing of a fortune of around a million dollars, this is in any case a strange form of democracy." p. 5.

${ }^{16} \mathrm{Idem}$. "The reorganization on the national scale is accompanied by a reorganization on a global scale, mainly through the new forms of imperialism and of colonialism, so-called indirect colonialism, which in many cases seems to be even more profitable that the direct previous forms of colonialism, which, at least in Latin America, have long since been replaced by - or, rather, taken over by - the indigenous ruling classes and the indigenous armies which do the job for metropolitan capitalist countries.” Pp. 6-7.

${ }^{17}$ Exceção a isso seria a indústria bélica, e outras estratégicas.

18 "Now this situation brings us face to face with the question of the responsibility of the intellectual. The choice is dictated to the intellectual by the two faces of the symbiosis of science and society, imagination and domination which we find today. This choice can be formulated in the following question. Man's reason, imagination, sensibility shall they be in the service of ever more efficient and prosperous servitude or rather or shall they serve to cut this link, releasing man's faculties and his imagination and sensibility from this profitable bondage? I believe that the militant students have made this choice and they have paid dearly for it. Today the real possibilities of human freedom are so real and the crimes of the society which prevents their realization are so blatant that the philosopher, the educator can no longer avoid taking sides, and that means alliance, solidarity with those who are no longer capable and no longer willing to have their future, to have their existence determined and defined by the requirements of the status quo. Determined and defined by the powers, the very powers that have made the world the mess, the threat and the lie which it is today. (...) If the philosopher, the educator still takes seriously his job of enlightenment he will find himself whether he wants it or not with those who want to give meaning and reality to the words and ideas he has taught during his life as educator, and not only academic meaning but a meaning to be fought for, a meaning to be lived for.". Marcuse, Herbert. "Beyond One-Dimensional Man”, In: Marcuse, 2001, p.119.

19 Marcuse, O homem unidimensional.

\section{REFERÊNCIAS BIBLIOGRÁFICAS}

ARONOWITZ, Stanley. “The Unknown Marcuse”, In: Social Text 58, Vol. 17, No.1, Spring 1999.

KELLNER, Douglas. A cultura da mídia. Trad. Ivone Castilho Benedetti. Bauru, Editora da Universidade do Sagrado Coração, 2001.

KELLNER, Douglas et al. Marcuse's Challenge to Education. Laham, Boulder, New York, Toronto, Plymouth - UK, Rowman and Littlefield publishers, 2009.

LOWREY, Annie. "Incomes flat in recovery, but not for the 1\%". The New York Times, Feb15, 2013. Disponível em http://www.nytimes.com/2013/02/16/business/economy/incomegains-after-recession-went-mostly-to-top-1.html no dia 10/09/2017.

MARCUSE, Herbert. Counterrevolution and Revolt. Boston, Beacon Press, 1972.

MARCUSE, Herbert. Tecnologia, guerra e fascismo. Douglas Kellner (ed). Trad. Maria Cristina Vidal Borba. São Paulo, Unesp, 1999.

MARCUSE, Herbert. Towards a Critical Theory of Society. Collected papers of Herbert Marcuse, vol. 2. Douglas Kellner (ed.). London and New York, Routledge, 2001. 
MARCUSE, Herbert $O$ homem unidimensional. São Paulo, Edipro, 2015.

MARCUSE, Herbert. Herbert Marcuse's 1974: Paris Lectures at Vicennes University from Marcuse Archives. Global Capitalism and Radical Opposition. Jansen, Peter-Erwin and Reitz, Charles. (eds). Introduction by Sarah Surak and afterwords by Douglas Kellner. Salisbury University, Maryland, USA, 2015.

MARCUSE, Herbert. Eros e civilização, São Paulo, Círculo do Livro, s/d.

REITZ, Charles e SPARTAN, Stepehen. "The policital economy of predation and counterrevolution: recalling Marcuse on the radical goals of socialism". In: REITZ, Charles (Ed.). Crisis and commonwealth: Marcuse, Marx, McLaren. Plymouth-UK, Lexington Books, 2015. 